\title{
Erratum to: How do UV radiation, temperature, and zooplankton influence the dynamics of alpine phytoplankton communities?
}

\author{
Craig E. Williamson • Courtney Salm • \\ Sandra L. Cooke $\cdot$ Jasmine E. Saros
}

Published online: 1 July 2010

(C) Springer Science+Business Media B.V. 2010

\section{Erratum to: Hydrobiologia \\ DOI 10.1007/s10750-010-0147-5}

The wrong Figure 2 was included in this article. The correct Fig. 2 and caption is given below:

The online version of the original article can be found under doi:10.1007/s10750-010-0147-5.

C. E. Williamson · S. L. Cooke

Department of Earth \& Environmental Sciences, Lehigh

University, Bethlehem, PA 18015, USA

C. E. Williamson $(\square)$

Department of Zoology, Miami University, Oxford,

OH 45056, USA

e-mail: craig.williamson@muohio.edu

C. Salm · J. E. Saros

Department of Biology, University of Wisconsin-La

Crosse, La Crosse, WI, USA

C. Salm · J. E. Saros

Department of Biology \& Ecology, Climate Change

Institute, University of Maine, Orono, ME 04469, USA

\section{S. L. Cooke}

Department of Biology, Duke University, Box 90025 ,

Durham, NC 27708, USA 
Fig. 2 Zooplankton exponential grazing rates (per six copepods and their nauplii per week) on phytoplankton at cool $(\mathrm{C}$, $8.3^{\circ} \mathrm{C}$ average) and warm (W, $11.7^{\circ} \mathrm{C}$ average) temperatures in the presence $(\mathrm{UV}+)$ and absence (UV-) of UVR for the four dominant phytoplankton species
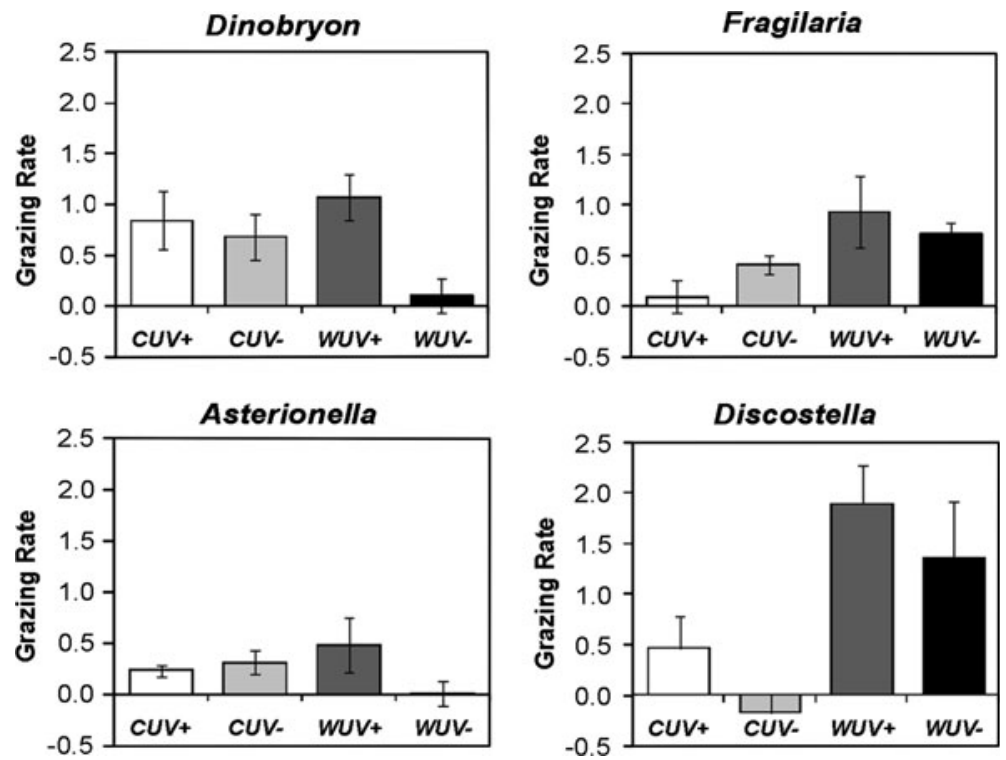